\title{
A Comprehensive System of Care Improves Neurologically- favorable Cardiac Arrest Survival
}

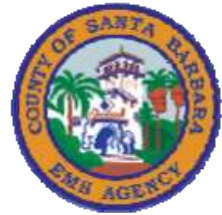

\author{
Angelo A. Salvucci, ${ }^{1}$ Lynn J. White, ${ }^{2}$ Raghav A Ravuri ${ }^{1}$ \\ ${ }^{1}$ Santa Barbara County Emergency Medical Services \\ California, USA; ${ }^{2}$ Global Medical Response; \\ HeartRescue Project; Colorado, USA
}

\section{GMR Medicine}

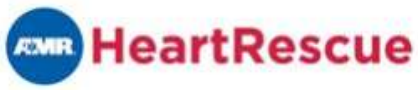

Objective: To evaluate the immediate and long-term results of introducing a comprehensive cardiac arrest management (CAM) system in a U.S. emergency medical services (EMS) jurisdiction according to structural description and outcome measures recommended by the U.S. Institute of Medicine (IOM).

Method: This is a before and after study in a community with a population of 450,000 . The goal of a cardiac arrest resuscitation system is "to increase the likelihood of survival with good neurologic function for any person who suffers a cardiac arrest."1 Unifying framework involves five groups: the public; EMS; hospitals and health care systems; researchers; and professional, education and advocacy organizations. ${ }^{1}$ In 2012 the community created a Cardiac Arrest Management (CAM) system involving initiatives to strengthen all the elements referenced above. Performance was tracked using the Cardiac Arrest Registry to Enhance Survival (CARES). We compared all rhythm cardiac-etiology survival with favorable neurological survival using Cerebral Performance Category (CPC) 1 [full recovery] or 2 [mild deficit, lives independently] - between the year prior and year after CAM introduction (immediate) and the two years prior to the six years after (sustained).

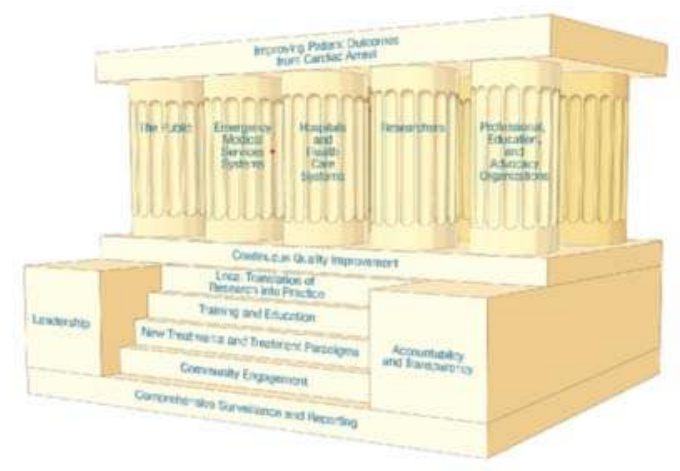

${ }^{1}$ IOM. 2015. Strategies to improve cardiac arrest survival: A time to act. Washington, DC: The National Academies Press
Results: There was an immediate and sustained increase in neurologically-favorable survival following implementation of CAM in 2013. Comparing the year before to the year after CAM introduction, CPC 1 or 2 survival increased from $7.5 \%$ to $15.7 \%$. Neurologically intact survival for all years following CAM implementation showed a statically significant difference over the CARES rates for the same years (see graph).

$\%$ Neurologically Intact Survival

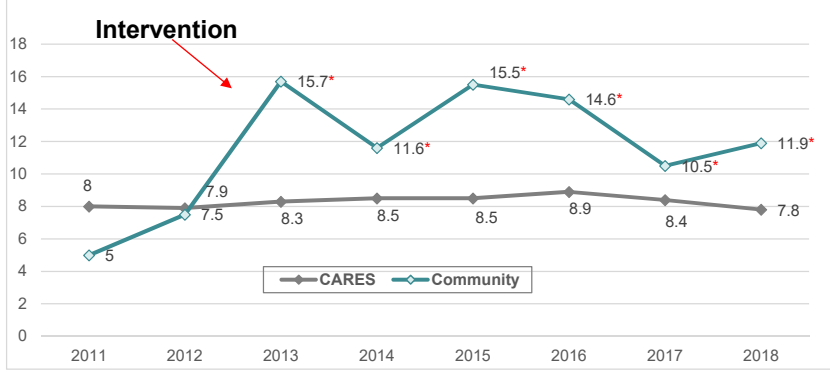

Conclusion: Introduction of CAM involving the elements described in the IOM report resulted in an immediate and sustained improvement in percentage of neurologically-favorable survival after sudden cardiac arrest. This provides further evidence for, and a roadmap to achieve, improved cardiac arrest outcomes.

\begin{tabular}{|c|c|}
\hline IOM Report & Cardiac Arrest Management (CAM) \\
\hline $\begin{array}{l}\text { Comprehensive } \\
\text { Surveillance and } \\
\text { Reporting }\end{array}$ & - CARES Registry \\
\hline $\begin{array}{l}\text { Community } \\
\text { Engagement }\end{array}$ & $\begin{array}{l}\text { - Hands-Only CPR Training } \\
\text { - Public Access AED Program }\end{array}$ \\
\hline $\begin{array}{l}\text { New Treatments and } \\
\text { Treatment Paradigms }\end{array}$ & $\begin{array}{l}\text { - Continuous Chest Compressions } \\
\text { - Low-Volume Bag-Mask Ventilations }\end{array}$ \\
\hline Training and Education & $\begin{array}{l}\text { - Feedback-Enhanced CPR Training \& } \\
\text { Testing } \\
\text { - Choreographed EMS Treatment Protocols }\end{array}$ \\
\hline $\begin{array}{l}\text { Local Translation of } \\
\text { Research into Practice }\end{array}$ & $\begin{array}{l}\text { - Minimizing Pre/Post Defibrillation Intervals } \\
\text { - Post-ROSC Protocols }\end{array}$ \\
\hline $\begin{array}{l}\text { Continuous Quality } \\
\text { Improvement Programs }\end{array}$ & $\begin{array}{l}\text { - } 100 \% \text { case review } \\
\text { - CPR quality metrics }\end{array}$ \\
\hline Leadership & $\begin{array}{l}\text { - Coordinated System-wide oversight } \\
\text { - Multi-agency participation }\end{array}$ \\
\hline $\begin{array}{l}\text { Accountability and } \\
\text { Transparency }\end{array}$ & $\begin{array}{l}\text { - Presentation of results to oversight } \\
\text { committee of all stakeholders }\end{array}$ \\
\hline
\end{tabular}

